\title{
EXTRACTION OF SOYA BEAN OIL FOR THE FORMULATION OF OIL AND EMULSION PAINT
}

\author{
J.A Arewa, E.O Alor, and E Akpoguma \\ Chemical Engineering Department, Federal University of Technology Minna, \\ Minna, Niger State. \\ DOI: $10.31364 /$ SCIRJ/v6.i12.2018.P1218596 \\ http://dx.doi.org/10.31364/SCIRJ/v6.i12.2018.P1218596
}

\begin{abstract}
This research work was on the dried seeds of soya bean which was crushed and sieved into fine powdered. The powder sample was weighed $(70 \mathrm{~g})$ and collected into a clean cellophane bag to prevent contamination. Oil was extracted from the powdered soya bean seed, the colour of oil was pale yellow and the percentage oil content of the soybean seed was found to be $28.57 \%$ per 70 gusing $250 \mathrm{ml}$ of $100 \% \mathrm{n}$-hexane as solvent. The mixture set was left for two days (48hours) before the extracted oil/solvent were collected. The oil was further separated from the solvent through distillation and heating at a temperature of 60$80^{\circ} \mathrm{C}$. The distilling solvent was trapped in the thimble, while the oil remained in the round bottle flask of the distillation apparatus. Analysis was carried out on the oil and the result ware recorded. Two different paints were produced using the soya bean oil; Firstly, emulsion paint was formulated with the oil been used directly as the resin (binder). Secondly, the oil was further refined by reacting with glycerol at a temperature of $250-260^{\circ} \mathrm{C}$ in order to convert the oil to it monoester. The product formed was further polymerized with phthalic anhydride (benzene-1,2-dicarboxylic anhydride) to produce the alkyd resin. Oil (gloss) paint was produced using the alkyd resin produced as a binder. From the analyses carried out on both paints, it showed that the oil paint has a density of $1.21 \mathrm{~g} / \mathrm{cm}^{3}$,specific gravity 1.21 , drying time $22 \mathrm{hrs}$, opacity $5.4 \mathrm{~m}^{2} / \mathrm{L}$ and the emulsion paint also has the following properties, density $1.32 \mathrm{~g} / \mathrm{cm}^{3}$, specific gravity 1.32 , drying time $26 \mathrm{hrs}$, opacity $6.2 \mathrm{~m}^{2}$. The oil and emulsion paints conformed to both the NIS and PMAN standards.
\end{abstract}

Keywords: Soybean Oil, Emulsion paint and Oil paint.

\section{INTRODUCTION}

Paints could be described as a colloidal mixture of chemical substances which when spread over a surface in a thin layer, gives rise to a solid, cohesive and adhesive film. Until recently, paint is a term used to describe a number of substances that consist of a pigment suspended in a liquid or paste vehicle such as oil and water. Paint is a word used to describe all liquid, liquefiable or mastic composition which is applied to a surface in a thin layer, which transformed or changed to a solid film (Flicck, 2011). Paint is the group of emulsions generally consisting of pigments suspended in a liquid medium used as decorative or protective coating, it has been manufactured even before now, since prehistoric times, but until recently they were highly expensive and thus were mainly used for artwork. It was from nineteenth century that houses have commonly been painted today, paints has been noticed for several purposes such as for coloring and protecting many surfaces, including houses, cars, road marking and underground storage vessels. Each of these surfaces mentioned above require a different composition of paint.Paint is the group of emulsions generally consisting of pigments suspended in a liquid medium used as decorative or protective coating. Two types of paint are generally recognized today, which are water based paint, and solvent based paint. Water based paint, as the name implies are emulsions of paint ingredients dissolved mostly in waster as solvent. Solvent based paint contains proportionally higher quantities of organic solvent such as aromatic ketones etc. for dissolving the different types of binders (Morgan, 2011). 
Paint consists of several components, each of which has its own purpose to affect the properties of paints and paint film formed on the surface. It primarily contains: pigment and fillers, binder or film former (resin), extender, solvent or thinner (diluent) and additives (Materials and applications, 2013).

Pigments and fillers are granular solids added in the paint for colour. Fillers are granular solids also added to give toughness, texture, special properties or to reduce the cost of the paint. Pigments can be classified as either natural or synthetic. Natural pigments include various clays, calcium carbonate, mica, silica and talc while synthetics include: engineered molecules, calcined clays, precipitated calcium carbonate and synthetic pyrogenic silicas (Morgan, 2011).

The colour of oil paint is derived from small particles of coloured pigments mixed with the carrier. Some of the earliest known pigments are: charcoal (black), iron oxide (rust red) and gypsum (white). Common pigment types include mineral salts such as white oxides (zinc, titanium and the red to yellow cadmium pigments) (Flicck, 2011).

The binder (resin)/Film former is the film forming component of paint. Binders are liquid polymeric or resinous materials that are used in coating to hold pigments and additives together to provide and to enable the coating and determine the performance of the film including flexibility, durability and chemical resistance. It is the only component that is always present among all the various types of formulations. The resin in paints, are the binders or adhesives which keeps the colours, additives and other ingredients together, to give a protective surface when the paint dries. The binder imparts properties such as gloss, durability, flexibility and toughness. Binders include synthetic or natural resins such as alkyds, acrylics, vinyl-acrylics, vinyl acetate/ethylene (VAE), polyurethanes, polyesters, melamine resins, epoxy, silanes and siloxanes or oils. The purpose of this research is to improve the quality of the resin using low cost soya bean oil as alternative for high cost oils like linseed oil, and other, this research involved the extraction of oil from soya bean seed, to produce wall emulsion paint using this oil as resin (binder) and to produce alkyd resin (binder) from this oil for the production of oil paint, some analyses were carried out, on both the oil and emulsion paint, to determine their, drying times, opacities, specific gravities, densities, viscosities and compared to standard.

Extenders can be anything from lime, chalk, sulphates, to carbonates, depending on the type of paint. They are sometimes referred to as pigment extenders and are known as false pigments. They are inorganic material in powder form which has low refractive index and consequently little obliterating power. They are used as constituents of paints to adjust the properties of the paints. Extenders improve the working and film forming properties of the paint and aid to prevent settlement on storage (Nigeria Industrial Standard (1) 1989). They are obtained from natural materials that are mined and grounded into a fine powder. They are generally white in colour and have no effect on the colour of wall emulsion paints (Flusher, 2012).

\section{SOYA BEAN OILS AS A LOCAL BASED RAW MATERIAL}


Soya bean oil is one of the most readily available and is a very low cost vegetable oils in Nigeria today. For many years, soya bean oil has been a major ingredient in making alkyd resin (binder), which are dissolved in a solvent to form a vehicle for oil paints making. While the production of alkyd resins, finished paints and coatings may involve proprietary formulations, the basic chemistry of converting a soyabean oil into analkyd resin under heat and pressure is well represented on the chemical reaction below (soynewuses.org).

$($ Propane $-1,2,3$-triol + Triglyceride of fatty acid $(\mathrm{g}$ mol $))=$

( Benzene -1,2-dicarboxylic Anhydride + monoglyceride +water)= alkyd resin

Soya bean is one of the major agricultural products in Nigeria, characterized by pale color, low odor, and low acidity, low cost, minimize fire risk, environmentally friendly, solvent free, and serve as a time regulator. Based on the challenges observed above, this research work will seek to find "The possibility of producing a quality gloss paints that will be affordable, safe and appealing to users."

\section{COMPOSITION OF SOYA BEAN}

Table 1.0: Composition of Soya bean Oil.

\begin{tabular}{lcc}
\hline Fatty acid & Symbol & Weight $\%$ \\
\hline Lauric & $12: 0$ & 4.5 \\
Myristic & $14: 0$ & 4.5 \\
Palmitic & $16: 0$ & 11.6 \\
Stearic & $18: 0$ & 2.5 \\
Oleic & $18: 10$ & 21.1 \\
Linoleic & $18: 2$ & 52.4 \\
Linolenic & $18: 3$ & 7.1 \\
& &
\end{tabular}

(Source: Wahnon, 2011)

\section{METHODOLOGY}

\section{Sample collection and Pre-treatment.}

The soya beans seed were purchased from Bosso market Minna Niger State, Nigeria. The soybean seeds were pretreated by cleaning, air drying, and dehulling (the kernel was removed from the seed and then dried for three days). The dried seeds were then ground to powdery form by the use of mortar and pestle for easy solvent contact or chemical penetration during extraction operation for better extraction.

Soxhlet apparatus was used to extract oil from it using n-hexane as the solvent. The percentage of oil extracted from it per $70 \mathrm{~g}$ of the ground soybean seed was found to be $28.57 \%$. At the end of the several extraction carried out, $130 \mathrm{~g}$ of the extracted oil was 
used to successfully produce very good quality emulsion paint. The oil was further refined by reacting with glycerol at a temperature of $250-260^{\circ} \mathrm{C}$ in order to convert the oil to it monoester. The product formed was further polymerized with phthalic anhydride (benzene-1,2-dicarboxylic anhydride) to produce the alkyd resin which was also used to successfully produce very good quality oil (gloss) paint.

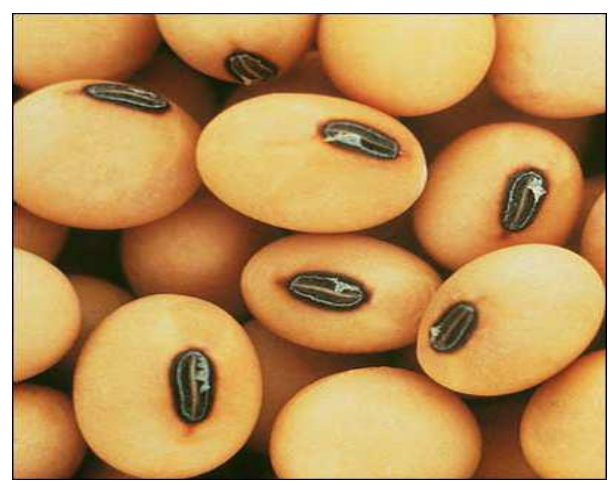

Plate1.0: SOYA BEAN SEED

\section{PROCEDURE FOR PAINT PRODUCTION}

Table 1.1: Procedure for paint production

\begin{tabular}{lll}
\hline Steps & Emulsion paint & Oil paint
\end{tabular}

1

3

4

5
The binder (soybean oil) and the emulsifier were mixed in a medium (one liter of water) in a container.

The filler and the pigment were added into the mixture in step 1 and stirred vigorously to prevent air-solid interface.

Additives were introduced into the mixturein2

After procedures above was completed, it was ensured that the above mixture was thoroughly mixed. Biocide was then added to the mixture to serve as preservative.

The physical properties such as opacity test, drying time, density, specific gravity and density were analyzed so as to conform to specification
The binder (alkyd resin) from soybean oil, pigment, fillers and additives were mixed in a container so as to form a viscous material.

The mixture above was transferred to a different container and the following were added into the container solvent (turpentine), driers, and plasticizers.

Coarse particles were removed through the process of clarifying and straining.

After procedures above was completed it was ensured that the above mixture was thoroughly mixed. Formaling was then added to the mixture to serve as preservative.

The physical properties such as opacity test, drying time, specific gravity and density were check/control so as to conform to specification. 


\section{ANALYSIS OF PAINT PROPERTIES}

Density: A sample of the paint produced was carefully transferred into a $25 \mathrm{ml}$ bottle capacity which was filled to the top. The empty bottle was first weighed as well as the bottle and the paint inside it. This was determined using the relationship;

Density $=\frac{(\text { weight of empty bottle }+ \text { sample })-(\text { weight of empty bottle }}{\text { volume of the sample }}\left(\mathrm{g} / \mathrm{cm}^{3}\right)$

Drying time: $25 \mathrm{ml}$ of the paint sample was to paint a board and the drying time was noted using a stop watch from the time of application to the time of drying.

Opacity: A board was primed with the paint produced and dried at room temperature. The brush to be used dipped into the paint sample produced before it was dipped into the $25 \mathrm{ml}$ beaker to prevent the brush from taking too much of the paint sample. The brush was used to paint the board and the area of the surface covered by the paint was noted. It was determined using the relation;

Opacity $=\frac{\text { area of painted surface }}{\text { volume of paint applied }}\left(\mathrm{m}^{2} / \mathrm{L}\right)$

Specific gravity: This is the ratio of the density of a substance to the density (mass of the same volume) of a reference substance (water) both at specified temperature.

Procedure: An empty density bottle was weighed with its stopper as $\mathrm{w}_{0}$. The bottle was filled with water and weighed as $\mathrm{w}_{1}$. The bottle was then emptied and dried before it was filled with the produced paint and weighed as $\mathrm{w}_{2}$.

The specific gravity was calculated using the relation:

$$
\text { Specific gravity }=\frac{w 2-w 0}{w 1-w 0}
$$

Where; $\quad \mathrm{w}_{2}=$ weight of paint + density bottle

$\mathrm{w}_{1}=$ weight of water + density bottle

$\mathrm{w}_{0}=$ weight of empty density bottle

\section{VII.RESULTS AND DISCUSSIONS}

Table 1.2: Result for oil paint analysis

\begin{tabular}{|c|c|c|c|}
\hline Parameters & Values & NIS standards & PMAN standard \\
\hline Density & $1.21 \mathrm{~g} / \mathrm{cm}^{3}$ & $1.2-1.5 \mathrm{~g} / \mathrm{cm}^{3}$ & $1.2-1.4 \mathrm{~g} / \mathrm{cm}^{3}$ \\
\hline Specific gravity & 1.21 & $1.3-1.5$ & $1.3-1.4$ \\
\hline
\end{tabular}


Drying time

Opacity
$22 \mathrm{hrs}$

$5.4 \mathrm{~m}^{2} / \mathrm{L}$
20-24 hours

$24 \pm 2$ hours

Table 1.3: Result for emulsion paint

\begin{tabular}{llcc}
\hline Parameters & \multicolumn{1}{c}{ Values } & PMAN standard & NIS standard \\
\hline Density & $1.32 \mathrm{~g} / \mathrm{cm}^{3}$ & $1.2-1.4 \mathrm{~g} / \mathrm{cm}^{3}$ & $1.2-1.5 \mathrm{~g} / \mathrm{cm}^{3}$ \\
Specific gravity & 1.32 & $1.3-1.4$ & $1.3-1.5$ \\
Drying time & $26 \mathrm{hrs}$ & $24 \pm 2$ hours & $20-24$ hours \\
Opacity & $6.2 \mathrm{~m}^{2} / \mathrm{L}$ & $5-8 \mathrm{~m}^{2} / \mathrm{L}$ & $5-8 \mathrm{~m}^{2} / \mathrm{L}$
\end{tabular}

DRYING TIME: The drying time of paint depends on the environment, mainly on temperature and humidity. The result revealed that the emulsion paint had the drying surface time of 26 hours while that of oil paint is 22 hours which is in conformity with the standard ( $24 \pm 2$ hours). The paint film applied on a brushed tinplate pane became hard dry in not more than 26 hours for emulsion paint and in not more than 22 hours for oil paint from the time of application.

OPACITY: Small quantity of high quality paint covers a given surface area whereas a paint of low quality requires a large volume to give coverage to the surface. These paints were tested to have good opacity and were able to cover well at not more than two coatings in accordance to the standard.

SPECIFIC GRAVITY: The specific gravity of the emulsion paint was found to be 1.32 while that of oil paint was found to be 1.21 , the specific gravities of both oil and emulsion paint conformed to NIS and PMAN standards which show that the paints is well granulated.

DENSITY: The density of paint is determined by the amount of color (pigment) used. After the analysis on both paints it was found that the density of emulsion paint was $1.32 \mathrm{~g} / \mathrm{cm}^{3}$ and that of oil paint was $1.21 \mathrm{~g} / \mathrm{cm}^{3}$. The densities of both paint fall within the standards of NIS and PMAN.

\section{CONCLUSION}

Soya bean oil was successfully used directly as resin (binder) in the preparation of emulsion paint and was also successfully converted into alkyd resin in the preparation of oil paint. The drying performance of the resin appears quite good when used directly for the formulation of the emulsion paint and when converted to alkyd resin and used for the formulation of oil paint. The hard drying time 26 hours and 22 hours for emulsion and oil paint respectively are in conformity with the standard (NIS and 
PMAN), drying paint time. From the other analyses carried out(density, specific gravity and opacity), it could be established that the emulsion and oil paint conformed to standard and could be used for both decorative and protective purposes.

\section{REFERENCES}

Flick Ernest, W. (2011). Handbook of Paint Raw Materials, $2^{\text {nd }}$ ed. Noyes Data Corp.

Morgans, W.M. (2011). Outlines of Paint Technology. $3^{\text {rd }}$ edition, Wiley and Sons, p 23-38.

Nigeria Industrial Standard, (1989).Solvent for Paint.

Flusher, F.K. (2012).The Industrial Analysis of Soybeans Oil and its Components, $6^{\text {th }}$ edition, Wiley, McGrawhill company, New York, p 123-126.

Spurgeon, A. (2006).Watching Paint Dry: Organic Solvent Syndrome in late Twentieth Century Britain. Med Hist. 50(2): 167188.

$\underline{\text { www.essentialchemicalindustry.org/materials-and-applications/paints.html }}$

https://en.m.wikipedia.org/wiki/painthttps://en.m.wikipedia.org/wiki/painthttp://pcimag.com/articles/84936-uv-curableacrylic-urethane-coatings

Nigerian Industrial Standard, 1990. (NIS) 238: Udc 667.6 standard for paints and varnishes part 6: Test Methods for paints and Varnishes. 